\title{
A Meta-analysis of Virtual Team Communication Based on IPO Model
}

\author{
Yongmei Liu ${ }^{1}$ Xi Yan ${ }^{1}$ Yuhua Sun ${ }^{1}$ \\ ${ }^{1}$ Department of Management Science and Engineering, Business School, Central South \\ University, Changsha, Hunan, China \\ Email: liuyongmeicn@yahoo.com.cn,yanxionline@yahoo.com.cn,syhyxt@126.com
}

\begin{abstract}
Communication plays a central role in virtual team performance, but its research results have not always been in agreement with each other. Using a general IPO model, this paper proposed hypotheses from the perspective of Media Synchronism Theory, and conducted a meta-analysis to test the relationships among virtual team input, process and output variables. The paper also offered implications for future research and practice in conclusion.
\end{abstract}

Keywords: virtual team, communication, meta-analysis

\section{Introduction}

Advanced technology and globalization promoted the extensive use of virtual team (VT). The last decades have witnessed a rapid growth in research on the input, process and output variables in virtual team (VT), which has led to an abundance of findings and practical suggestions. However, these conclusions have not always been in agreement with each other, because relationships among input, process and output variables vary substantially in magnitude and direction. Questions existed for years did not come to consistent answers, like does media really contribute or restrain team effectiveness, how team size and task type affect the communication in VTs, what is the roles of communication, trust in VT process etc.

Even though all definitions of VT have emphasized the central position of communication, there are rare studies which have investigated the relationships among input, process and output variables in VT from the perspective of communication. Especially behavior factors such as trust, cohesion, etc, which are crucial to traditional teams, will more close related to communication in virtual settings. Therefore, it is necessary to explore the relationships among input, process and output variables that centering on communication from another angle. As the best theory to study communication process and performance $^{[1]}$, Media Synchronism Theory (MST) will be adopted in present study to explain and analyze VT communication process and related influence factors.

The aim of the present study is to propose hypotheses based on the IPO model and MST. In order to synthesize and integrate all the findings and conclusions from previous studies on virtual teams (VTs), a quantitative meta-analysis was carried out to test these hypotheses. Results discussion, study limitations, practical implications and directions for future research are also proposed.

\section{Research Model and Hypotheses}


This study builds upon Hackman's wildly accepted Input-Process-Output (IPO) model to investigate variable relations. Based on MST that emphasizes the fit between media capacity and communication process, we choose four input variables and four process variables. As shown in figure 1, this study investigates the effect of input/output variables on team effectiveness, and hypotheses will be presented later.

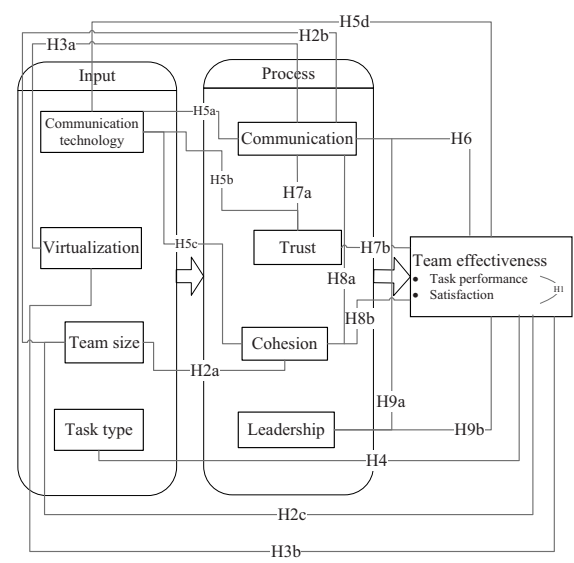

Fig. 1: Research Model.

\subsection{Team Effectiveness}

The main purpose of VT research is to achieve high team effectiveness. Effective teams are characteristic as higher quality output and members' gratification and satisfaction with the working experience $^{[2]}$. Therefore, task performance and satisfaction are the two main aspects of effectiveness. In practice, performance improvement is at the cost of satisfaction, and higher satisfaction will not always promote performance, thus there is a tradeoff between performance and satisfaction. From the perspective of communication, team performance and satisfaction can help each other forward. Due to the lack of face-to-face communication and verbal cues, high performance will ensure mutual trust and the willingness to continue work together in future, which has a positive effect on team satisfaction ${ }^{[3]}$; While higher satisfaction will improve cohesion, communication and trust in VTs, which will finally improve task performance. Therefore, we hypothesize that:

H1: Team performance positively related to team satisfaction.

\subsection{Virtual Team Input Variables}

Input variables are either team characteristics or essential conditions for task accomplishment before formal communication, like team size, virtualization, task type and communication technology.

\subsubsection{Team Size}

Team size is the number of team members each team has. It's an important structural variable with potential influences on the quality of teams' collaboration and project success, team communication process and task performance $^{[4]}$.

Some studies showed that large teams seem to be more appropriate for solving complex tasks in uncertain and complicated environment, since only large teams can provide enough resources, expertise, professional skills and knowledge. Meta-analysis also showed that large team has more innovation ${ }^{[5]}$. While other studies demonstrated that small teams will behave better in communication frequency, cohesion and performance. A quasi-experimental research indicated that dyadic teams performed better and used less communication in arriving at task solution, while large teams seem more difficult in interaction ${ }^{[6]}$. As team size grows, individual links and the possibility team members keep away from one another may dramatic increase, which will lead to decrease in team cohesion and 
performance, moreover, team size significant negatively related to working quality $^{[7]}$ and can influence trust and conflict. The increased relationship and task conflicts in large teams will cause decrease in cohesion and task performance. Therefore, we hypothesize that:

H2a: Team size negatively related to cohesion;

$\mathrm{H} 2 \mathrm{~b}$ : Team size negatively related to communication effectiveness;

$\mathrm{H} 2 \mathrm{c}$ : Team size negatively related to team performance.

\subsubsection{Virtualization}

Virtualization is a continuous variable that indicates the extent between team members fully time-space dispersed and live under the same physical roof with all communication occurs FTF. Researchers usually use team members' physical proximity to measure virtualization $^{[8]}$. The more proximate members are, the less virtualization team will be. Literatures indicated that virtualization moderated the relationships among trust, communication, conflict, cohesion and task performance.

Virtual environment makes members isolated and uncertain about their tasks and relationships ${ }^{[9]}$. Which means communication is more crucial for performance in $\mathrm{VTs}^{[7]}$. As virtualization increases, team members may feel more apart from each other and communications will remarkably reduce, it seems more difficult to solve problem and control process. Therefore, we hypothesize that:

H3a: Team member proximity positively related to communication.

H3b: Team member proximity positively related to team performance.

\subsubsection{Task Type}

In VT studies, researchers generally classified tasks into idea-generation, intellective and decision-making tasks based on the extent of team interaction and coordination. Research showed whatever task is, team members performed the same in communication and effectiveness [10]; while others indicated that satisfaction in idea-generation tasks is higher than that in decision-making tasks ${ }^{[11]}$.

It is not convincing to compare performance solely according to task type, because what matters is not task itself, but the different needs for communication and coordination each task implied ${ }^{[12]}$. From the perspectives of communication and MST, we distinguish tasks into high/low interdependent tasks according to the extent of coordination needs. As task interdependence increase, both the need for team interaction and communication will increase. According to Task Technology Fit Theory ${ }^{[13]}$, the adoption of high synchronous media will improve team effectiveness in high interdependent tasks; and for low interdependent tasks, adoption of high synchronous media will instead increase the complexity of communication process and cost, and low synchronous media is more appropriate. Therefore, we hypothesize that:

H4a: For teams with high interdependent task, communication frequency is high, and using high synchronous media will produce high team effectiveness.

H4b: For teams with low interdependent task, communication frequency is low, and using low synchronous media will achieve high team effectiveness.

\subsubsection{Communication Technology}

Communication technology is always the focus of VT research, and there appear many media theories explaining its 
mechanisms and effects. Media Richness Theory(MRT)is the most popular ${ }^{[14]}$. Based on MRT, there are huge amount of studies comparing team performance and satisfaction in FTF and CMC settings ${ }^{[10]}$, but the results is not always consistent.

Some studies showed that FTF teams have higher productivity and more feedbacks, but CMC teams could generate more ideas ${ }^{[12]}$. CMC will increase the time required to reach an agreement, but if we consider all moderator variables, VT can be as effective as FTF team ${ }^{[15]}$. While other studies proved that information exchange in VTs is not as effective as in FTF teams, and FTF teams performed better than VTs ${ }^{[16]}$. In a word, empirical tests of MRT are not consistent.

The emergence of Media Synchronization Theory (MST) and Fit-Appropriation Theory (FAT) contributes a lot in explaining the interaction effects of media capability and task communication process ${ }^{[17]}$. According to FAT, the fit between media capability and communication goal will affect team performance, and media synchronization will influence team effectiveness. Research indicated that whatever task it is, synchronous media performed better than asynchronous media, but asynchronous media has a more clear communication structure ${ }^{[18]}$. MST indicated that low synchronous media (e.g. e-mail) might be more appropriate to convey information, and they will show more in-depth problem analysis and generate more ideas of reasoning ${ }^{[19]}$. While high synchronous media (e.g. FTF) are more suitable for complex tasks whose goal is to converge information and achieve shared understanding [17]. The fit between communication process (conveyance or convergence) and communication technology determined whether there is an improvement in communication, trust, cohesion and team effectiveness. Therefore, we hypothesize that:

H5a: When goal of communication is convey/converge information, low/high synchronous media will lead to higher performance;

H5b: When goal of communication is convey/converge information, low/high synchronous media will lead to higher trust;

H5c: When goal of communication is convey/converge information, low/high synchronous media will lead to higher cohesion;

H5d: When goal of communication is convey/converge information, low/high synchronous media will lead to higher task performance and team satisfaction.

\subsection{Virtual Team Process Variables}

The present study chooses communication, trust, cohesion and leadership as process variables in virtual teams(VTs).

\subsubsection{Communication}

Communication is a process in which individuals create and share information with each other to achieve shared understanding $^{[20]}$. Relationship development, shared understanding, and trust are important antecedents of team communication and collaboration.

Team communication is a significant predictor of team satisfaction. Researchers pointed out that the most satisfied members existed in team with effective communication. Some studies showed that communication in VTs and FTF teams are the same, but members in FTF situations reveal higher satisfaction $^{[21]}$. A survey also showed that FTF communication still present the highest level of communication satisfaction $^{[22]}$.

Due to task-oriented and lack of nonverbal cues, VTs' communication 
process is not as smoothly as that in FTF teams, which lead to low satisfaction in VTs. Thus, communication in VTs is especially important. With increased communication, satisfaction and team performance will increase accordingly. Researchers also found that communication frequency could predict team performance ${ }^{[23]}$. We argue that communication will strengthen the ties among members, eliminate unnecessary misconceptions and misunderstandings, and finally ensure the smooth and efficient in task completion. Research hypothesis is proposed:

H6: Communication positively related to team effectiveness.

\subsubsection{Trust}

Trust is critical to team success. Traditionally, Trust is the result of individual judgments of past behavior and will develop gradually over time ${ }^{[24]}$. The features of VT make it more difficult to build trust. In FTF teams, social interaction among members helps them understand and form relationships with each other, and build trust gradually. In CMC situations, team members located in different places which is more difficult to develop social relations and more likely to suffer collapse, misunderstandings and misconceptions, Therefore, the formation of trust in VTs will take a longer time ${ }^{[25]}$. In addition, some studies showed that social relation reductions in VTs make trust is not as important as in FTF teams. However, high level of trust will promote communication, satisfaction and task performance $^{[26]}$.

We argue that goal clarity makes teams get into collaborative works quickly ${ }^{[26]}$, and then trust gradually formed, and communication plays a key role in this whole process. Although some scholars pointed out that high level of trust could lead to reduction in communication in later stage of team development, in short, active communication will prompt high trust that will facilitate communication, satisfaction and performance improvement. Therefore, we hypothesize that:

H7a: Trust and communication show a positive relation;

$\mathrm{H} 7 \mathrm{~b}$ : Trust positively related to team effectiveness.

\subsubsection{Cohesion}

Cohesion is the most important variable in small group research. It indicates the extent of team members agree with each other and the team's level of concentration $^{[27]}$. Previous studies showed that cohesion positively related to team performance and satisfaction ${ }^{[3,28]}$, and communication has a significant direct impact on relationship building and cohesion $^{[3]}$.

It was pointed out that physical dispersion will restrain cohesion development. In addition, members' understanding of cohesion in VTs is different from that in FTF teams ${ }^{[29]}$. After comparing the cohesion in $\mathrm{CMC}$ and traditional teams, researchers indicated that CMC can help VTs to improve their cohesion, productivity and task performance. Therefore, we hypothesize that:

H8a: Team cohesion positively related to communication;

H8b: Team cohesion positively related to team effectiveness.

\subsubsection{Leadership}

Leaders play an important role in team development. Flat structure in VTs makes it smoother to exchange information. Leadership style will have a significant impact on VT communication. Transactional and transformational leadership styles are two common styles. Transactional style emphasizes the transactions or exchange among members, 
whereas transformational style enhances the awareness of his followers through moral ideas and appealing thoughts, such as freedom, fairness etc. Transformational leadership earned the most attention and will have impacts that are more powerful on performance in VTs. Once Transformational leadership dominates a VT, team members will perform better ${ }^{[30]}$.

This paper argues that different styles of leadership will affect communication atmosphere, and transformational leadership will increase communication, and achieve higher team effectiveness. Therefore, we hypothesize that:

H9a: Compared with transactional leadership style, transformational leadership will promote higher communication effective;

H9b: Compared with transactional leadership style, transformational leadership style will lead to higher team performance.

\section{Research Methodology}

This paper adopted meta-analysis to test above hypotheses. Meta-analysis focuses on the direction and magnitude of the effects across studies. Previous studies showed that, meta-analysis is a useful tool for review study and hypothesis test ${ }^{[5]}$.

\subsection{Literature Search and Coding}

We conducted an extensive literature search in Proquest ABI/Inform, ISI web of knowledge, and EBSCO to identify studies published before January 2010 using several keywords like "communication and virtual team", "distributed team" etc. According to study hypotheses, the following inclusion criteria was developed: studies are quantitative studies reporting factors related to VT communication, and come from social science, psychology, education, management science. After reading each abstract, two authors applied decision rules and 135 articles included. After downloaded these full texts, two authors read them, and applied the second round inclusion criteria below: only studies that reported a team-level relationship related to communication and other behavior factors, and reports effect size indices are convertible to correlation coefficients were included. At last, 64 articles were included.

Authors read the articles carefully and coded all variables related, collected correlation coefficient and scale reliability, if there is no direct correlation coefficient, collected other statistics that can be converted into correlation coefficient using converting equations ${ }^{[31]}$.

\subsection{Meta-Analytic Procedure}

We followed the procedures of Hunter and Schmidt (1990) to correct study artifacts, and divided reported correlation by the square root of the product of the reliabilities of the two variables. After correcting all correlation coefficients and sample size, we applied Comprehensive Meta Analysis V2 to accumulate study findings, homogeneity test and final effect size (r-value), and choose random effects model to analyze the data. Details show in Table 1.

\subsection{Results and Discussion}

As the two aspects of team effectiveness, performance and satisfaction significantly related $(\mathrm{r}=.593, \mathrm{p}<0.05)$, which indicates that team performance has a highly positive impact on team satisfaction. When faced with high performance, team members' satisfaction will be improved, and also more satisfaction with each other will correspondingly increase team performance.

Results show that team size negatively related to cohesion $(\mathrm{r}=-0.118, \mathrm{p}<0.05)$, but not significantly related to 
performance $(\mathrm{r}=-0.101, \mathrm{p}>0.05), \quad$ large team means increased communication cost and misunderstanding, reduced efficiency, even for teams emphasizing innovation, too large team will still restrain performance. We argue that the insignificant relations between team size and performance may be influenced by performance measure standard. When confronted with brainstorm tasks which performance standard is idea-generation, team performance will benefit from large team size; but if tasks emphasizing coordination, large teams will cost more time and energy which can be harmful to team performance.

Statistics only shows that task interdependence significantly related to performance $(\mathrm{r}=0.267, \mathrm{p}<0.05)$, but our study did not explore other relations behind it, such as whether the fit between task interdependence and media can improve performance. Therefore, we argue that there are moderators or mediated variables exist which should be considered in future.

Moreover, communication technology positively related to communication $(\mathrm{r}=0.585, \mathrm{p}<0.05)$, outcome satisfaction $(\mathrm{r}=0.389, \mathrm{p}<0.05), \quad \operatorname{trust}(\mathrm{r}=0.320, \mathrm{p}<0.05)$, cohesion $(\mathrm{r}=0.383, \mathrm{p}<0.05) \quad$ and performance $(\mathrm{r}=0.366, \mathrm{p}<0.05)$, but not significantly related to team satisfaction $(r=0.325, p>0.05)$. These results affirmed the importance of media in VTs, but due to task-oriented and less social communication, VTs concerned more about performance than satisfaction or relationship building. In addition, empirical studies cannot simulate real team process and members are always temporary, their goal is to accomplish an assigned task in a setting period but to emphasize process satisfaction and relationship building.

At last, $\quad \operatorname{trust}(\mathrm{r}=0.308, \mathrm{p}<0.05)$, cohesion $(r=0.674, p<0.05)$ and leadership style $(\mathrm{r}=0.467, \mathrm{p}<0.05)$ all related to performance. Virtual team members are different with each other, the only way they build trust is through communication media. Even though trust building in VTs is more difficult than that in traditional teams, members in VTs will have higher performance if trust is built. As the most important aspects of VTs, cohesion is very crucial to team development and achievement. Magnitudes of effect size show that trust, cohesion and leadership style are particularly important to performance, which need to be strengthen in practice.

What most sets our thinking is that there is no significant relations between communication and task performance $(r=0.328, \quad \mathrm{p}>0.05) . \quad$ As a process variable, communication influence information exchange and sharing. However, communication is not the determinant of task performance, because some performance relies on communication while other performance just depends on members' intelligence. In a word, communication is a necessary condition but not sufficient condition of task performance.

No significant relations exist between member proximity and communication/ performance, but the directions of effect size indicated that the more members close to each other, the higher communication and performance will be, which is in accordance with previous studies that virtualization will impede the promotion of communication, trust and cohesion, and finally lead to performance decrease.

Because of the limitation of sample size, we did not examine $\mathrm{H} 2 \mathrm{~b}, \mathrm{H} 7 \mathrm{a}, \mathrm{H} 8 \mathrm{a}$ and $\mathrm{H} 9 \mathrm{a}$, which need further study.

\section{Conclusion}

This paper conducted a meta-analysis to test hypotheses about VT communication and related behavioral factors from the 
perspective of Media Synchronism Theory. Most of these hypotheses are supported.

Meta-Analytic results imply that in practice, virtual teams should maintain proper team size, pay more attention to distinguishing different tasks and their needs for media, select appropriate media combinations according to different settings, and strengthen trust, cohesion and transformational leadership style in training. Specially, cohesion is very important in virtual teams, and it should be concerned carefully in further practice.

\begin{tabular}{|c|c|c|c|c|c|c|c|c|c|}
\hline $\mathbf{H}$ & \multicolumn{2}{|c|}{ Related Variables } & \multirow{2}{*}{$\begin{array}{c}\boldsymbol{k} \\
9\end{array}$} & \multirow{2}{*}{$\begin{array}{c}\boldsymbol{n} \\
517\end{array}$} & \multirow{2}{*}{$\frac{N}{6235}$} & \multirow{2}{*}{$\frac{r}{0.593 *}$} & $95 \% \mathrm{CI}$ & \multirow{2}{*}{$\frac{\mathbf{Z}}{6.702}$} & \multirow{2}{*}{$\frac{\text { Sig. }}{0.00}$} \\
\hline H1 & performance & satisfaction & & & & & $0.448, \quad 0.707$ & & \\
\hline $\mathrm{H} 2 \mathrm{a}$ & Team size & cohesion & 4 & 400 & 1734 & $-0.118^{*}$ & $-0.214, \quad-0.019$ & -2.329 & 0.02 \\
\hline $\mathrm{H} 2 \mathrm{c}$ & Team size & Performance & 8 & 764 & 7492 & -0.101 & $-0.236, \quad 0.039$ & -1.418 & 0.16 \\
\hline $\mathrm{H} 3 \mathrm{a}$ & Member-prox & Communication & 4 & 518 & 2269 & 0.021 & $-0.194,0.233$ & 0.188 & 0.85 \\
\hline $\mathrm{H} 3 \mathrm{~b}$ & Member-prox & Performance & 7 & 662 & 3358 & 0.185 & $-0.094,0.437$ & 1.303 & 0.19 \\
\hline $\mathrm{H} 5 \mathrm{a}$ & Commu-tech & Communication & 4 & 84 & 417 & $0.585 *$ & $0.322,0.764$ & 3.908 & 0.00 \\
\hline $\mathrm{H} 5 \mathrm{~b}$ & Commu-tech & Trust & 3 & 134 & 456 & $0.320 *$ & $0.155, \quad 0.468$ & 3.708 & 0.00 \\
\hline \multirow[t]{2}{*}{$\mathrm{H} 5 \mathrm{c}$} & Commu-tech & Cohesion & 3 & 251 & 960 & $0.383 *$ & $0.258, \quad 0.495$ & 5.656 & 0.00 \\
\hline & Commu-tech & Performance & 15 & 634 & 2643 & $0.366^{*}$ & $0.267, \quad 0.458$ & 6.785 & 0.00 \\
\hline $\mathrm{H} 5 \mathrm{~d}$ & Commu-tech & Satisfaction & 3 & 108 & 404 & 0.325 & $-0.062, \quad 0.627$ & 1.656 & 0.10 \\
\hline $\mathrm{H}_{8} \mathrm{a}^{+}$ & Communication & Cohesion & 一 & - & - & - & - & - & - \\
\hline $\mathrm{H} 8 \mathrm{~b}$ & Cohesion & Performance & 7 & 508 & 2314 & $0.674 *$ & $0.288, \quad 0.872$ & 3.073 & 0.00 \\
\hline $\mathrm{H} 9 \mathrm{a}^{+}$ & leadership style & Communication & 一 & - & - & - & - & - & - \\
\hline $\mathrm{H} 9 \mathrm{~b}$ & leadership style & performance & 4 & 145 & 778 & $0.467 *$ & $0.235, \quad 0.648$ & 3.721 & 0.00 \\
\hline
\end{tabular}

* Effect size is significant at .05 level $(\mathrm{p}<0.05){ }^{+}$correlation is not examined due to sample size is not big enough $(n<3)$; The relation between communication and process satisfaction is homogenous, and it is not show in table 1. (prox=team member proximity; Commu-tech=communication technology; outcome-satis=outcome satisfaction) $\mathrm{H}$ : hypothesis; $k=$ number of studies; $n=$ total sample size for all studies combined based on number of teams; $N=$ total sample size for all studies combined based on number of individual participants, $r=$ the final corrected correlation effect size; $95 \% \mathrm{CI}=2.5 \%$ lower and $97.5 \%$ upper limits of $95 \%$ confidence interval.

Table 1: Meta-analysis results.

What unexpected is the insignificant relations between communication and team performance. As the core of VT, communication is very crucial, but the mechanism of its impact on performance is still not clear. Studies on communication are not adequate which need further deep and dynamic research.

At last, although we believe that the present meta-analytic findings contribute to the virtual team literature, some limitations still exist such as sample size limitation, only team-level coefficients studied etc. which need further consideration and improvement.

\section{References}

[1] A.Dennis, R. Fuller, and J. Valacich, "Media, tasks, and communication processes: A theory of media synchronicity," MIS QUARTERLY, 2008. 32(3).

[2] P.Gabriele, P. Anne, and I. Blake, "irtual teams: team control structure, work processes, and team effectiveness," Information Technology \& People, pp. 359,2004. 17(4).

[3] C.Lin, C. Standing, and Y.C. Liu, "A model to develop effective virtual teams," Decision Support Systems, pp. 1031-1045,2008. 45(4).

[4] R.Gallupe, et al., "Electronic brainstorming and group size," The 
Academy of Management Journal, pp. 350-369,1992. 35(2).

[5] Hu"lsheger, U.R., N. Anderson, and J.F. Salgado, "Team-Level Predictors of Innovation at Work: A Comprehensive Meta-Analysis Spanning Three Decades of Research," Journal of Applied Psychology ,2009. 94(5).

[6] G. Karayaz, and C.B. Keating, "Virtual team effectiveness using dyadic teams," Picmet '07: Portland International Center for Management of Engineering and Technology, Vols 1-6, Proceedings, pp. 2593-2603,2007.

[7] M.Hoegl, H. Ernst, and L. Proserpio, "How teamwork matters more as team member dispersion increases," Journal of Product Innovation Management, pp. 156-165,2007. 24(2).

[8] J.Kratzer, R. Leenders, and J.M.L. Van Engelen, "Managing creative team performance in virtual environments: an empirical study in 44 R\&D teams," Technovation, pp. 42-49,2006. 26(1).

[9] M.Workman, "The proximal-virtual team continuum: A study of performance," Journal of the American Society for Information Science and Technology, pp. 794-801,2007. 58(6).

[10] V.Savicki, M. Kelley, and D. Lingenfelter, "Gender, group composition, and task type in small task groups using computer-mediated communication," Computers in Human Behavior, pp. 549-565,1996. 12(4).

[11]A.R.Dennis, and B.H. Wixom, "Investigating the moderators of the group support systems use with meta-analysis," Journal of Management Information Systems, pp. 235-257,2001. 18(3).
[12] S.G. Straus, and J.E. McGrath, "Does the medium matter-the interaction of task type and technology on group performance and member reactions," Journal of Applied Psychology, pp. 87-97,1994. 79(1).

[13] M.M.Montoya, et al., "Can You Hear Me Now? Communication in Virtual Product Development Teams," Journal of Product Innovation Management, pp. 139-155,2009. 26(2).

[14]R. Daft, and R. Lengel, "Organizational information requirements, media richness and structural design," Management Science, pp. 554-571,1986.

[15]B.B.Baltes, et al., "Computer-Mediated Communication and Group Decision Making: A Meta-Analysis," Organizational Behavior and Human Decision Processes, pp. 156-179,2002. 87(1).

[16]R. Hightower, and L. Sayeed, "Effects of communication mode and prediscussion information distribution characteristics on information exchange in groups,"Information Systems Research, pp. 451,1996. 7(4).

[17] D. Dorrie, and S.V. Joseph, "Virtual teams in and out of synchronicity," Information Technology \& People, pp. 323,2006. 19(4).

[18]R. Ramón, and G.C. Susan, "Effects of task interdependence and type of communication on performance in virtual teams," Journal of Managerial Psychology, p. 261,2005. 20(3/4).

[19] A.I.Shirani, M.H.A. Tafti, and J.F. Affisco, "Task and technology fit: a comparison of two technologies for synchronous and asynchronous group communication," Information \& Management, pp. 139-150,1999. 36(3).

[20]E.M.Rogers, "Communication Technology,"The Free Press pp.288, 1986 . 
[21]E.W.Merrill, S. Lutfus, and H. Ross, "Virtual teams versus face-to-face teams: An exploratory study of a Web-based conference system," Decision Sciences, pp. 975,1997. 28(4).

[22] M.Gerda, "Virtual Teams: Just a Theoretical Concept or a Widely Used Practice?,"The Business Review, Cambridge, pp. 186,2007. 7(1).

[23]P.A.Gloor, et al., "Finding collaborative innovation networks through correlating performance with social network structure,"International Journal of Production Research, pp. 1357-1371,2008. 46(5).

[24] L.P.Robert, A.R. Dennis, and Y.T.C. Hung, "Individual Swift Trust and Knowledge-Based Trust in Face-to-Face and Virtual Team Members," Journal of Management Information Systems, pp. 241-279,2009. 26(2).

[25] J.Wilson, S. Straus, and B. McEvily, "All in due time: The development of trust in computer-mediated and face-to-face teams," Organizational Behavior and Human Decision Processes, pp. 16-33,2006. 99(1).

[26]P.E.Bierly, E.M. Stark, and E.H. Kessler, "The Moderating Effects of
Virtuality on the Antecedents and Outcome of NPD Team Trust," Journal of Product Innovation Management, pp. 551-565,2009. 26(5).

[27] L.Chidambaram, "Relational development in computer-supported groups" Mis Quarterly, pp. 143-165,1996.

[28]A.Chang, and P. Bordia, "A multidimensional approach to the group cohesion-group performance relationship," Small Group Research, pp. 379,2001. 32(4).

[29] W.Salisbury, "Cohesion in virtual teams: validating the perceived cohesion scale in a distributed setting," ACM SIGMIS Database, pp. 155,2006. 37(2-3).

[30]R.Purvanova, and J. Bono, "Transformational leadership in context: Face-to-face and virtual teams," The Leadership Quarterly, 2009.

[31]J.Wu, and A. Lederer, "A meta-analysis of the role of environment-based voluntariness in information technology acceptance," MIS Quarterly, pp. 419-432,2009. $33(2)$. 